\title{
IgG AVIDITY WESTERN BLOT USING TOXoplasma gondii rGRA-7 CLONED FROM NUCLEOTIDES 39-711 FOR SERODIAGNOSIS OF ACUTE TOXOPLASMOSIS
}

Poonam S. DESHPANDE(1)\#, Dupadahalli KOTRESHA(1), Rahmah NOORDIN(1), Muhammad Hafiznur YUNUS(1), Geita SAADATNIA(1), Majid GOLKAR(3), Sabariah OSMAN(1), Izzati Zahidah Abdul KARIM(1) \& Fatemeh GHAFFARIFAR(2)

\begin{abstract}
SUMMARY
Toxoplasmosis is an important cause of congenital infection. The present study was performed to evaluate the usefulness of recombinant (r) GRA-7 cloned from nucleotides (n) 39-711 in discriminating between acute and chronic toxoplasmosis. First, commercial IgM, IgG and IgG avidity ELISAs were used to determine the serological profile of the sera. Serum samples were from 20 symptomatic patients with acute infection (low IgG avidity, IgM positive), 10 with chronic infection (high IgG avidity, IgM negative) and 10 with indeterminate IgG avidity (IgM positive) which were tested for IgG avidity status with an in-house developed IgG avidity Western blot using the rGRA-7 recombinant antigen. All 20 sera from cases of probable acute infection showed bands which either faded out completely or reduced significantly in intensity after treatment with $8 \mathrm{M}$ urea, whereas the band intensities of the 10 serum samples from chronic cases remained the same. Of the 10 sera with indeterminate IgG avidity status, after treatment with $8 \mathrm{M}$ urea the band intensities with six sera remained the same, two sera had completely faded bands and another two sera had significantly reduced band intensities. Discrimination between acute and chronic toxoplasmosis was successfully performed by the in-house IgG avidity Western blot.
\end{abstract}

KEYWORDS: Toxoplasmosis; IgG avidity; rGRA-7 (n39-711); Western blot.

\section{INTRODUCTION}

Toxoplasmosis is an infection caused by the obligate intracellular parasite Toxoplasma gondii which infects a large variety of domestic and wild mammals, including humans ${ }^{11}$. T. gondii infection in humans is generally asymptomatic and induces a self-limiting disease. However, in pregnant women, immunosuppressed patients and those with ocular involvement, the clinical outcome can be very serious. An acute infection with $T$. gondii acquired during the first trimester of pregnancy can result in intrauterine transmission to the unborn fetus, severe fetal and neonatal complications including mental retardation, retinochoroiditis, blindness, and death ${ }^{13,17}$. Therefore it is crucial to identify the gestational age of primary infection for the clinical management of pregnant women, since the severity of fetal toxoplasmosis decreases and maternal to fetal transmission rate increases as gestational age progresses ${ }^{7,26}$. The diagnostic challenge is presented when Toxoplasma-specific IgG and IgM antibodies are found in first sample after conception, since estimation of the time of infection is crucial to determine whether the fetus is at risk ${ }^{8}$.

Routine diagnosis of $T$. gondii infection relies mainly on serological detection of specific anti-Toxoplasma $\operatorname{IgG}$, IgM and $\operatorname{IgA}$ antibodies ${ }^{24}$, but the results of these assays are not able to estimate the time of infection with accuracy ${ }^{6,10}$. An assay measuring the antigen-binding avidity of $\operatorname{IgG}$ antibodies against $T$. gondii has proven to be a highly useful procedure for serological diagnosis of Toxoplasma infections ${ }^{3,4,16}$. This is especially apparent in situations where timing and differentiation of primary and secondary infections is crucial ${ }^{17}$. Using IgG avidity assay, acute infection can be diagnosed using a single serum specimen, and further primary infection can be distinguished from secondary (recurrent or reactivated) infections. In the past many different methods have been to measure IgG avidity, however most of these are laborious and unsuitable for diagnostic laboratories ${ }^{14}$. Also in nearly all these kits various preparations of lysed whole-cell $T$. gondii antigens are utilized, which might be contaminated by non-parasitic materials. One way to overcome this problem is to use recombinant antigens, which can improve the standardization and performance of the IgG avidity assay in terms of quality and consistency.

As the avidity test is dependent on the presence of specific $\mathrm{IgG}$, it is very important to use an antigen which elicits humoral response at the acute stage of infection. In a previous study, we have identified rGRA7 (P29) sequence of n39-711 as a molecule that reacted strongly with IgG antibody in acute sera samples, and thus holds good potential to be used in discriminating between probable acute and chronic cases of $T$. gondii infection ${ }^{12}$. Therefore in the present study, we developed an in- 


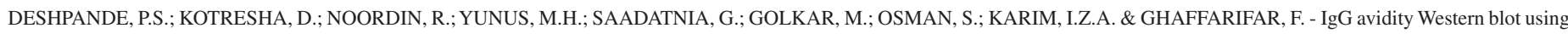
Toxoplasma gondii rGRA-7 cloned from nucleotides 39-711 for serodiagnosis of acute toxoplasmosis. Rev. Inst. Med. Trop. Sao Paulo, 55(2): 79-83, 2013.

house modified immunoblot technique (IgG avidity Western blot) using rGRA-7 recombinant antigen (n39-711) to discriminate between high and low IgG antibody avidity in sera samples of $T$. gondii-infected patients.

\section{MATERIALS AND METHODS}

The study was performed during the period from June 2010 to February 2011 at the Institute for Research in Molecular Medicine, Penang, Malaysia.

Serum samples: These comprised samples from pregnant women or patients suspected of toxoplasmosis and previously tested for the presence of IgM and/or IgG antibodies to T. gondii. The samples were previously collected with prior informed consents of the individuals. Approval for use of the banked samples was obtained from Universiti Sains Malaysia Human Research Ethics Committee, which conforms to the principles of the Helsinki Declaration of 1975, as revised in 1983. A total of 40 human serum samples were analyzed and divided into three groups based on serological profiles derived after performing commercially available immunoassays, namely Platelia ${ }^{\mathrm{TM}}$ Toxo IgG Indirect EIA, Platelia ${ }^{\mathrm{TM}}$ Toxo IgM, and Platelia ${ }^{\mathrm{TM}}$ IgG avidity-ELISA (Bio-Rad, France). The cut-off OD for low avidity result in the Platelia IgG avidity-ELISA was 0.400 .

One group of sera (Group 1) consisted of 20 human serum samples from patients with probable acute phase toxoplasmosis. The patients had clinical symptoms consistent with acute toxoplasmosis and demonstrated the following serological profile : optical density (OD) of IgM-ELISA > 1.000, IgG-ELISA positive, Avidity Index (AI) of IgG-avidity ELISA < 0.250 . The second group of sera (Group II) consisted of 10 human serum samples from individuals with serological profile indicative of chronic infection i.e. positive for IgM-ELISA and IgG-ELISA, AI of IgG-avidity ELISA $>0.500$. The third group of sera (Group III) consisted of 10 human serum samples from individuals who were suspected of having toxoplasmosis, and the serological profile was as follows i.e. positive for IgM-ELISA and IgG-ELISA, AI of IgG-avidity ELISA was between 0.400 to 0.500 which suggested intermediate IgG avidity. All human serum samples were stored at $-20{ }^{\circ} \mathrm{C}$ until tested.

Toxoplasma recombinant antigen: rGRA-7 was previously cloned from nucleotides 39-711 (amino acids 14-236), GenBank accession No HM016952. The antigen was expressed efficiently in bacterial cells as insoluble protein and was purified by affinity chromatography ${ }^{14}$. Briefly, recombinant Escherichia coli was induced with isopropyl- $\beta$-Dthiogalactopyranoside (IPTG), centrifuged, and suspended in lysis buffer (50 mM sodium dihydrogen phosphate, $500 \mathrm{mM}$ sodium chloride, 10 $\mathrm{mM}$ imidazole and $0.1 \%$ Triton-X 100) containing cocktail of protease inhibitor (Roche, Germany, $14.8 \mu \mathrm{g} / \mathrm{mL}$ ) and lysozyme (Amresco, Solon, Ohio, $0.5 \mathrm{mg} / \mathrm{mL}$ ). The cells were lysed using French Press $40 \mathrm{~K}$ (Thermo Spectronic, USA) followed by centrifugation at 12,000 $\mathrm{g}, 4$ ${ }^{\circ} \mathrm{C}$ for 30 minutes to separate the supernatant and pellet. Subsequently the pellet was dissolved in denaturing lysis/binding buffer (7M Urea, $100 \mathrm{mM} \mathrm{NaH}_{2} \mathrm{PO}_{4}, 10 \mathrm{mM}$ Tris-HCl, $\mathrm{pH}$ 8.0) and centrifuged to pellet any insoluble debris and the soluble fraction was used for further purification steps. After DNase I treatment, the protein fraction was incubated with Ni-NTA resin. After loading, the column was washed with denaturing washing buffer ( $8 \mathrm{M}$ urea, $100 \mathrm{mM} \mathrm{NaH} \mathrm{PO}_{4}, 10 \mathrm{mM}$ Tris- $\mathrm{HCl}, \mathrm{pH}$ 6.3) and eluted with denaturing buffer ( $\mathrm{pH}$ 5.9) and elution buffer ( $\mathrm{pH}$ 4.5). Purified fractions were pooled and elution buffer was exchanged with storage buffer $50 \mathrm{mM}$ Tris- $\mathrm{HCl}, 150 \mathrm{mM} \mathrm{NaCl}, 5 \%$ Glycerol, $\mathrm{pH}$ 8.0) using Vivaspin column, cut-off $3 \mathrm{kDa}$ (Sartorius, Germany) and the concentrated protein was stored at $-80^{\circ} \mathrm{C}$.

IgG Avidity ELISA : This test was carried out using Platelia ${ }^{\mathrm{TM}} \mathrm{TOXO}$ IgG AVIDITY kit (Bio-Rad, France) in conjunction with Platelia ${ }^{\mathrm{TM}}$ TOXO IgG assay kit. This test has to be used only on samples that demonstrate an anti-T. gondii IgG concentration higher or equal to $9 \mathrm{IU} /$ $\mathrm{mL}$ with Platelia ${ }^{\mathrm{TM}}$ TOXO IgG. Avidity controls and patient sera with a concentration of anti- $T$. gondii IgG between 9 and $80 \mathrm{IU} / \mathrm{mL}$ were diluted to $1 / 101$. Sera from patients with a concentration of anti- $T$. gondii IgG equal or higher than $80 \mathrm{IU} / \mathrm{mL}$ were diluted to 1/808. Each control and patient serum sample was treated with control solution and dissociating solution for 15 minutes at room temperature. After incubation, both solutions and dissociated $\operatorname{IgG}$ antibodies were removed by through washing. Then $200 \mu \mathrm{L}$ conjugate (anti-human IgG conjugated with horseradish peroxidase) was added to the microplate wells and incubated at $37{ }^{\circ} \mathrm{C}$ for further one hour. The unbound conjugate was removed by washing at the end of the incubation and $200 \mu \mathrm{L}$ of substrate was added in each well. After incubation for 30 minutes at room temperature the enzymatic reaction was stopped by adding $100 \mu \mathrm{L}$ of stop solution. The optical density readings were obtained with a spectrophotometer set at $450 / 620 \mathrm{~nm}$, and are proportional to the amount of IgG antibodies to $T$. gondii. An Avidity index (AI) of $\geq 0.500$ was considered an indicator of anti-Toxoplasma $\mathrm{IgG}$ with high avidity, an AI of $<0.400$ indicated low avidity, and an AI between 0.400 to 0.500 suggested intermediate/ borderline avidity.

IgG Avidity Western blot: $1 \mu \mathrm{g}$ of rGRA-7 was loaded per well on $10 \%$ SDS-PAGE and the protein was transferred onto $0.45 \mu \mathrm{m}$ nitrocellulose membrane (Bio-Rad, France). The membrane was then blocked with 5\% fat-free milk in PBS for one $\mathrm{h}$ and then washed thrice with wash buffer (PBS-T). The membrane was cut in the form of strips and was incubated in duplicate with single serum samples (diluted 1:800 in PBS) for one hour at room temperature followed by one hour at $37^{\circ} \mathrm{C}$ with gentle rocking. After incubation, one strip of the duplicate serum was incubated with PBS-T and other strip was washed with 8M Urea in PBS-T for 5, 10 and 15 minutes. Finally, all the nitrocellulose strips (with and without urea treatment) of each serum sample were subjected to three washing cycles with PBS-T for 5, 10 and 15 minutes. The washed strips were incubated with secondary antibody peroxidase conjugated mouse anti-human IgG (Invitrogen) diluted at 1:10,000 for one hour at room temperature. Following being washed three times with PBS-T, the strips were developed using chemiluminescence blotting substrate (Thermo Scientific, USA) and Kodak films (Kodak, USA).

\section{RESULTS}

Fig. 1 shows the result of the Western blot using T. gondii rGRA7 probed with human serum samples from Groups 1 and II, when subjected to a washing solution with or without $8 \mathrm{M}$ urea. The antigenic bands with all 20 sera from Group I (acute infection) either faded out completely (n $=11)$ or the intensity reduced significantly $(n=9)$ when washed with 8 $\mathrm{M}$ urea, as compared with washing without urea (Table 1A). On the other hand antigenic bands with all 10 sera from Group II (chronic infection) did not change in intensity with or without treatment with $8 \mathrm{M}$ urea (Fig. 1, Table 1B). Meanwhile, with 10 sera from Group III, when treated with $8 \mathrm{M}$ urea two of the sera showed band intensities which completely faded, 



Toxoplasma gondii rGRA-7 cloned from nucleotides 39-711 for serodiagnosis of acute toxoplasmosis. Rev. Inst. Med. Trop. Sao Paulo, 55(2): 79-83, 2013.

two sera had significantly reduced band intensities and six sera showed band intensities which remained the same (Table 1C).

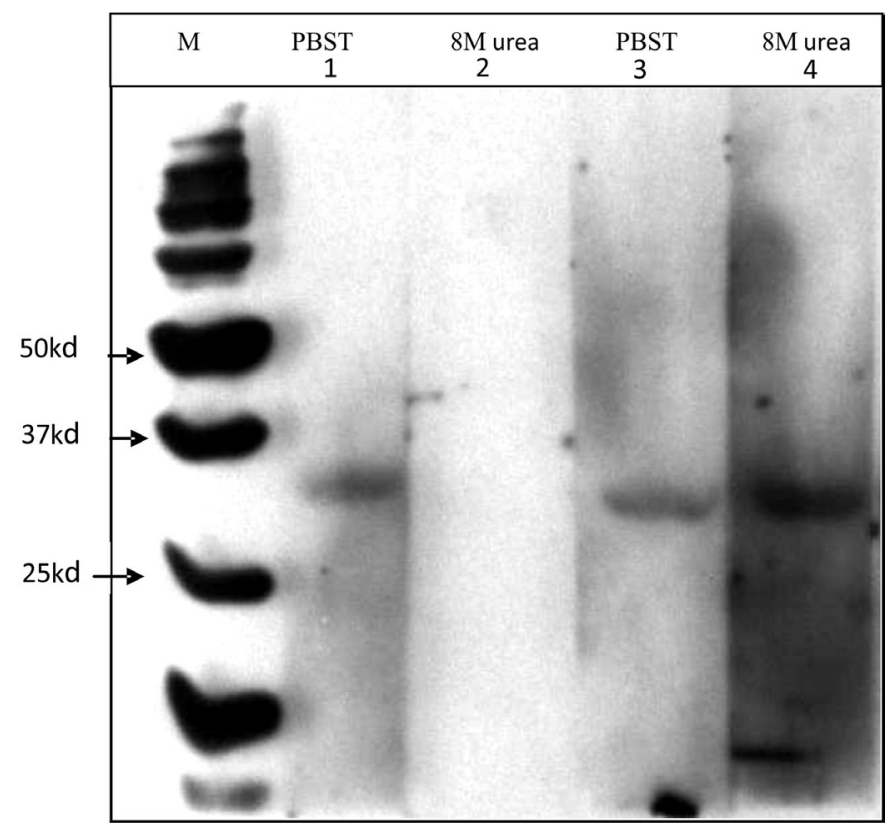

Fig. 1 - T.gondii rGRA-7 (n39-711) antigen recognized by specific IgG in sera of acute and chronic phase of infection. $\mathrm{M}=$ Marker, 1 = acute phase sera without urea treatment, $2=$ same sera as 1 but treated with $8 \mathrm{M}$ urea; $3,4=$ chronic phase sera without and with $8 \mathrm{M}$ urea treatment respectively.

\section{DISCUSSION}

The measurement of IgG avidity for serodiagnosis of Toxoplasma infection has been shown to be a very useful confirmatory procedure for discriminating between recently acquired and distant infections $\mathbf{s}^{3,4,7,20}$. Accurate diagnosis is particularly important for pregnant women for timely therapeutic decisions ${ }^{4}$. Since the presence of anti-Toxoplasma $\mathrm{IgG}$ or IgM antibodies is not a very reliable indicator of infection acuteness, pregnant mothers presenting with these antibodies in their first sample constitute the greatest challenge for accurate diagnosis. The avidity of specific IgG antibodies is usually low in the beginning of infection and increases with time by antigen-driven B cell selection. A high IgG avidity index within the first trimester of pregnancy can usually exclude an infection acquired during gestation ${ }^{25}$. However it has been reported than in treated individuals, the $\mathrm{IgG}$ avidity maturation may be delayed ${ }^{15}$. In a study of 146 Japanese who were positive for T. gondii IgG antibody and either positive or equivocal for specific IgM, the investigations showed that testing the IgG avidity of the maternal blood combined with multiplex nested PCR of the amniotic fluid is very useful in diagnosing congenital toxoplasmosis ${ }^{27}$.

There are numerous test systems commercially available, and most are based on whole-cell T. gondii antigen. Avidity assays based on this antigen were reported to detect low or borderline (intermediate) avidity antibodies in many individuals with chronically infected individuals, whereas recombinant antigens produced more mature avidity indices in chronically-infected individuals, and can therefore better distinguish between acute and chronic infections ${ }^{18,21,23}$.
Table 1

Presence of band in IgG avidity Western blot using rGRA7 (n 39-711) with low (A), high (B) and intermediate (C) $\operatorname{IgG}$ avidity sera and two kinds of wash buffer

\section{(A) IgG avidity Western blot with low IgG avidity sera}

\begin{tabular}{ccccc}
\hline No. & Serum code & Avidity index & PBST wash & 8M Urea wash \\
\hline 1. & $\operatorname{Tg} 217$ & 0.1495 & + & faint + \\
2. & $\operatorname{Tg} 212$ & 0.2096 & + & - \\
3. & $\operatorname{Tg} 84$ & 0.1820 & + & faint+ \\
4. & Tg98 & 0.2130 & + & faint + \\
5. & Tg61 & 0.1807 & + & - \\
6. & Tg60 & 0.376 & + & - \\
7. & $\operatorname{Tg} 62$ & 0.2445 & + & faint + \\
8. & $\operatorname{Tg} 64$ & 0.1700 & + & faint + \\
9. & $\operatorname{Tg} 30$ & 0.261 & + & - \\
10. & $\operatorname{Tg} 66$ & 0.229 & + & - \\
11. & $\operatorname{Tg} 83$ & 0.323 & + & faint+ \\
12. & $\operatorname{Tg} 59$ & 0.2701 & + & - \\
13. & $\operatorname{Tg} 58$ & 0.250 & + & - \\
14. & $\operatorname{Tg} 21$ & 0.248 & + & - \\
15. & $\operatorname{Tg} 219$ & 0.237 & + & faint+ \\
16. & $\operatorname{Tg} 221$ & 0.217 & + & faint+ \\
17. & $\operatorname{Tg} 254$ & 0.258 & + & - \\
18. & $\operatorname{Tg} 225$ & 0.268 & + & - \\
19. & $\operatorname{Tg} 257$ & 0.259 & + & faint+ \\
20. & $\operatorname{Tg} 55$ & 0.223 & + & +
\end{tabular}

(B) IgG avidity Western blot with high IgG avidity sera

\begin{tabular}{ccccc}
\hline No. & Serum code & Avidity index & PBST wash & 8M Urea wash \\
\hline 1. & Tg50 & 1.032 & + & + \\
2. & Tg54 & 0.909 & + & + \\
3. & Tg102 & 0.778 & + & + \\
4. & Tg105 & 0.640 & + & + \\
5. & Tg106 & 0.605 & + & + \\
6. & Tg111 & 0.758 & + & + \\
7. & Tg116 & 0.795 & + & + \\
8. & Tg215 & 0.764 & + & + \\
9. & Tg 265 & 0.888 & + & + \\
10. & Tg80 & 0.516 & + & +
\end{tabular}

\begin{tabular}{ccccc}
\hline \multicolumn{5}{c}{ (C) IgG avidity Western blot with intermediate IgG avidity sera } \\
\hline No. & Serum code & Avidity index & PBST wash & 8M Urea wash \\
\hline 1. & Tg 101 & 0.419 & + & faint + \\
2. & Tg 103 & 0.415 & + & - \\
3. & Tg 104 & 0.491 & + & + \\
4. & Tg 114 & 0.488 & + & + \\
5. & Tg 119 & 0.412 & + & - \\
6. & Tg 166 & 0.438 & + & + \\
7. & Tg 177 & 0.423 & + & + \\
8. & Tg 239 & 0.403 & + & faint + \\
9. & Tg 240 & 0.478 & + & + \\
10. & Tg 241 & 0.409 & + & + \\
\hline
\end{tabular}

+: band present; faint +: faint band present; - : band absent. 


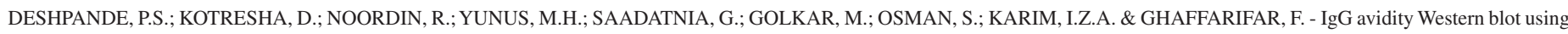
Toxoplasma gondii rGRA-7 cloned from nucleotides 39-711 for serodiagnosis of acute toxoplasmosis. Rev. Inst. Med. Trop. Sao Paulo, 55(2): 79-83, 2013.

The usefulness of single antigen based avidity assays has previously been reported by various investigators. MORCOLINO et al. ${ }^{18}$, investigated recognition of $\mathrm{p} 16, \mathrm{p} 32, \mathrm{p} 38$ by human serum in IgG immunoblotting avidity assay. They identified p38 band as a good antigenic marker for detecting low avidity $\operatorname{IgG}$ in acute toxoplasmosis, whereby there was significant decrease of their frequencies (from $80 \%$ to $0 \%$ ) after treatment with urea solution. ELYASI et al. ${ }^{5}$, evaluated the usefulness of avidity ELISA based on recombinant GRA-6 antigen for distinguishing between acute and chronic Toxoplasma infection, and they showed better clinical usefulness and performance of GRA6 avidity assay than the commercially available Euroimmune avidity ELISA for exclusion of recent infection of less than four months.

In an effort to improve discrimination between acute and chronic infections, we have developed a protein-denaturing assay for determining IgG avidity against rGRA-7 recombinant protein (14-236aa, n39-711). This is an extension of our previous study in which we have reported the diagnostic potential of this molecule for diagnosis of acute infection using IgG assay. When compared to rSAG1, the rGRA7 was able to better discriminate between acute and chronic toxoplasmosis, and showed higher specificity ${ }^{12}$. In the present report, we further evaluated the potential of rGRA-7 recombinant protein (14-236aa, n39-711) in an IgG avidity assay using an in-house Western blot technique which involves the dissociation of the antigen-antibody interaction with urea-containing washing solution. In a preliminary study (not described elsewhere in this report), washing solutions containing $6 \mathrm{M}$ and $8 \mathrm{M}$ were compared, the latter was found to show greater reduction in band intensity with low $\mathrm{IgG}$ avidity sera, and no difference in intensity with high IgG avidity chronic sera (data not shown). This observation differed from the report by MARCOLINO et al. ${ }^{18}$, which showed no difference in $\mathrm{IgG}$ avidity between the treatments with 6 and $8 \mathrm{M}$ urea solutions with samples from acute and chronic infections.

GRA7 is found in the parasitophorous vacuole and the cytoplasm of the tachyzoite infected host cell. This explains why IgG antibody response against GRA7 is potentially higher in early infection ${ }^{9}$ and thus could be a good candidate to be used for diagnosis of acute toxoplasmosis. BEGHETTO et $a l{ }^{2}$ used ELISA avidity with GRA7 cloned from nucleotides 72-309 (24-103aa) and showed 36.5\% mean avidity in serum samples collected after two months of infection. Meanwhile PFREPPER et al..$^{21}$ showed that at the beginning of IgG response, antibody to GRA7 (79-789 (1-236aa) and/or GRA8 were exclusively present in human sera, while those to MAG1 and SAG1 were not observed. In time course studies IgG antibody to GRA7 and GRA8 matured significantly earlier than SAG1 and MAG1. These recombinant antigens are being used in a commercial immunoblot avidity kit (recomLine, MIKROGEN, Germany).

The GRA7 protein has also been reported by others to react more with acute sera as compared to chronic sera ${ }^{1,19}$. PIETKIEWICZ et al. ${ }^{23}$ used GRA7 cloned from nucleotides 56-708(16-236aa) in combination with GRA1 and SAG1 recombinant proteins to differentiate between recent and late infection. The GRA7 segment used by PIETKIEWICZ et al. ${ }^{23}$ was similar, but not exactly the same, to that used in the present study. A cocktail of three recombinant proteins (rGRA1, rSAG1, rGRA7) was used by PIETKIEWICZ et al. ${ }^{23}$, thus the IgG avidity results using rGRA7 alone are not known. Furthermore, our previous results on rSAG1(used as part of the above antigen cocktail) differed from the results of another study by the same research team ${ }^{22}$. Our data showed that it was positive with $20 \%$ (4/20) of healthy seronegative individuals, thus not suitable for use in Toxoplasma diagnosis ${ }^{12}$, while PIETKIEWICZ et al. ${ }^{22}$ showed that it was not reactive $(0 / 19)$ with this group of individuals. The different Toxoplasma immunoassays used to determine the serological status of the individuals may explain the difference in results.

In this study, the usefulness of rGRA-7 cloned from nucleotides 39711 (14-236aa) in an IgG avidity Western blot assay was compared with results of commercially available Platelia IgG Avidity ELISA (BioRad, USA). With the sera of Groups I and II there was 100\% agreement of the avidity status between our in-house IgG avidity Western blot with the commercial ELISA kit. In addition, with Group III sera which showed intermediate results using the commercial kit, the $\operatorname{IgG}$ avidity Western blot was able to differentiate them into low and high IgG avidity groups. Thus in this study, the IgG avidity Western blot using rGRA7 (14-236aa) enabled categorization of all 40 serum samples into either low or high IgG avidity, without any indeterminate results. Nevertheless it would be necessary to test a much larger number of serum samples in order to confirm that the assay will solve or significantly reduce the problem of borderline results. A side by side comparison of the various reported cloned segments of rGRA7 using the same sera panel would be very useful in ascertaining the best gene segment for use in IgG avidity assay. In addition, development of an ELISA format of the IgG avidity assay based on rGRA7 (n39-711) would be useful in providing quantitative results that can facilitate inter-laboratory result comparisons. The development of a rapid lateral flow format of the test would be welcomed for use in settings lacking in facilities and trained personnel

In conclusion, this study showed the potential of discrimination between acute and chronic toxoplasmosis by an IgG avidity Western blot assay using GRA7 recombinant antigen cloned from the gene segment comprising nucleotides 39-711.

\section{RESUMO}

\section{Avidez do IgG pelo Western Blot usando o r GRA-7 do Toxoplasma gondii clonado de nucleotídeos 39-711 para sorodiagnóstico de toxoplasmose aguda}

Toxoplasmose é uma causa importante de infecção congênita. O presente estudo foi feito para avaliar o uso do recombinante (r) GRA-7 clonado de nucleotídeos (n) 30-711 para discriminar entre toxoplasmose aguda e crônica. Inicialmente IgM, IgG e ELISA avidez IgG comerciais foram usados para determinar o perfil sorológico do soro. Amostras de soro de 20 pacientes sintomáticos com infecção aguda (IgG avidez baixa, IgM positivo), 10 com infecção crônica (alta avidez IgG, IgM negativo) e 10 com avidez IgG indeterminada (IgM positivo) que foram testados para o status de avidez IgG com um doméstico Western Blot desenvolvendo avidez IgG usando o rGRA-7 antígeno recombinante. Todos os 20 soros de provável infecção aguda mostraram bandas que ou se apagaram completamente ou tiveram a sua intensidade significantemente reduzida após tratamento com uréia $8 \mathrm{M}$, enquanto as intensidades das bandas das 10 amostras de soros de casos crônicos permaneceram iguais. Dos 10 soros com status indeterminado de avidez de $\mathrm{IgG}$, após tratamento com uréia $8 \mathrm{M}$ a intensidade das bandas em seis soros permaneceram iguais, dois soros tiveram bandas apagadas completamente e dois outros tiveram significante redução da intensidade das bandas. Discriminação 
DESHPANDE, P.S.; KOTRESHA, D.; NOORDIN, R.; YUNUS, M.H.; SAADATNIA, G.; GOLKAR, M.; OSMAN, S.; KARIM, I.Z.A. \& GHAFFARIFAR, F. - IgG avidity Western blot using Toxoplasma gondii rGRA-7 cloned from nucleotides 39-711 for serodiagnosis of acute toxoplasmosis. Rev. Inst. Med. Trop. Sao Paulo, 55(2): 79-83, 2013.

entre toxoplasmose aguda e crônica foi feita com sucesso através do IgG avidez Western blot doméstico.

\section{ACKNOWLEDGEMENTS}

This study was funded by the Universiti Sains Malaysia Research University (RU) grant No. 1001/CIPPM/8130132. We would like to thank Tan Sin Yee for her technical help.

\section{REFERENCES}

1. Aubert D, Maine GT, Villena I, Hunt JC, Howard L, Sheu M, et al. Recombinant antigens to detect Toxoplasma gondii-specific immunoglobulin $\mathrm{G}$ and immunoglobulin $\mathrm{M}$ in human sera by enzyme immunoassay. J Clin Microbiol. 2000;38:1144-50.

2. Beghetto E, Buffolano W, Spadoni A, Del Pezzo M, Di Cristina M, Minenkova O, et.al. Use of an Immunoglobulin $\mathrm{G}$ avidity assay based on recombinant antigens for diagnosis of primary Toxoplasma gondii infection during pregnancy. J Clin Microbiol. 2003;41: 5414-8.

3. Candolfi E, Pastor R, Huber R, Filisetti D, Villard O. IgG avidity assay firms up the diagnosis of acute toxoplasmosis on the first serum sample in immunocompetent pregnant women. Diagn Microbiol Infect Dis. 2007;58:83-8.

4. Crucerescu E, Rodicalovin D. Study of specific IgG avidity as a tool for recent primary Toxoplasma gondii infection diagnosis. J Prev Med. 2002;10:56-62.

5. Elyasi H, Babaie J, Fricker-Hidalgo H, Brenier-Pinchart MP, Zare M, Sadeghiani G, et al. Use of dense granule antigen GRA6 in an Immunoglobulin G Avidity Test to exclude acute Toxoplasma gondii infection during pregnancy. Clin Vaccine Immunol. 2010;17:1349-55.

6. Francis JM, Joynson DH. Duration of specific immunoglobulin A antibody following acute toxoplasmosis as determined by enzyme immunoassay and immunosorbent agglutination assay. Eur J Clin Microbiol Infect Dis. 1993;12:556-9.

7. Gilbert R. Screening options in the management of congenital toxoplasmosis. Toxoplasmosis. CLI, June 2004. Available from: http://www.cli-online.com/fileadmin/ pdf/pdf_general/screening-options-in-the-management-of-congenital-toxoplasmosis. pdf

8. Iqbal J, Khalid N. Detection of acute Toxoplasma gondii infection in early pregnancy by IgG avidity and PCR analysis. J Med Microbiol. 2007;56:1495-9.

9. Jacobs D, Vercammen M, Saman E. Evaluation of recombinant dense granule antigen 7(GRA7) of Toxoplasma gondii for detection of immunoglobulin G antibodies and analysis of a major antigenic domain. Clin Diagn Lab Immunol. 1999;6:24-9.

10. Joss AWL. Diagnosis. In: Ho-Yen DO, Joss AWL, editors. Human toxoplasmosis. Oxford: Oxford Medical Publications; 1992. p.79-118.

11. Kotresha D, Noordin R. Recombinant proteins in the diagnosis of toxoplasmosis. APMIS 2010;118:529-42.

12. Kotresha D, Poonam D, Muhammad HafiznurY, Saadatnia G, Nurulhasanah O, Sabariah $\mathrm{O}$, et al. Recombinant proteins from new constructs of SAG1 and GRA7 sequences and their usefulness to detect acute toxoplasmosis. Trop Biomed. 2012;29:129-37.

13. Kravetz JD, Federman GD. Toxoplasmosis in pregnancy. Am J Med. 2005;118:212-6.
14. Lappalainen M, Hedman K. Serodiagnosis of toxoplasmosis. The impact of measurement of IgG avidity. Ann Ist Super Sanita. 2004;40:81-8.

15. Lefevre-Pettazzoni M, Bissery A, Wallon M, Cozon G, Peyron F, Rabilloud M. Impact of spiramycin treatment and gestational age on maturation of Toxoplasma gondii immunoglobulin G avidity in pregnant women. Clin Vaccine Immunol. 2007;14:23943

16. Liesenfeld O, Montoya JG, Kinney S, Press C, Remington JS. Effect of testing for IgG avidity in the diagnosis of Toxoplasma gondii infection in pregnant women: experience in a US reference laboratory. J Infect Dis. 2001;183:1248-53.

17. Montoya JG, Remington JS. Management of Toxoplasma gondii infection during pregnancy. Clin Infect Dis. 2008;47:554-66.

18. Morcolino PT, Silva DAO, Leser PG, Camargo ME, Mineo JR. Molecular markers in acute and chronic phases of human toxoplasmosis: determination of immunoglobulin G avidity by Western blotting. Clin Diag Lab Immunol. 2000;7:384-89.

19. Nigro M, Gutierrez A, Hoffer AM, Clemente M, Kaufer F, Carral L, et al. Evaluation of Toxoplasma gondii recombinant proteins for the diagnosis of recently acquired toxoplasmosis by an immunoglobulin G analysis. Diagn Microbiol Infect Dis. 2003;47:609-13.

20. Peterson E, Borobio MV, Guy E, Liesenfeld O, Meroni V, Naessens A, et al. European multicenter study of the LIAISON automated diagnostic system for determination of Toxoplasma gondii-specific immunoglobulin (IgG) and IgM and the IgG avidity index. J Clin Microbiol. 2005;43:1570-4.

21. Pfrepper KI, Enders G, Gohl M, Krczal D, Hlobil H, Wassenberg D, et al. Seroreactivity to and avidity for recombinant antigens in toxoplasmosis. Clin Diagn Lab Immunol. $2005 ; 12: 977-82$

22. Pietkiewicz H, Hiszczyńska-Sawicka E, Kur J, Petersen E, Nielsen HV, Stankiewicz M, et al. Usefulness of Toxoplasma gondii-specific recombinant antigens in serodiagnosis of human toxoplasmosis. J Clin Microbiol. 2004;42:1779-81.

23. Pietkiewicz H, Hiszczyńska-Sawicka E, Kur J, Petersen E, Nielsen HV, Paul M, et al. Usefulness of Toxoplasma gondii recombinant antigens (GRA1, GRA7 and SAG1) in an immunoglobulin $\mathrm{G}$ avidity test for the serodiagnosis of toxoplasmosis. Parasitol Res. 2007;100:333-7.

24. Remington JS, McLeod R, Desmonts G. Toxoplasmosis. In: Remington JS, Klein JO, editors. Infectious diseases of the foetus and new born infant. London: W.B. Saunders; 2000. p. 205-346

25. Robert-Gangneux F, Darde ML. Epidemiology of and diagnostic stratergies for Toxoplasmosis. Clin Microbiol Rev. 2012; 25:264-96. Doi: 10.1128/CMR.05013-11.

26. Sakikawa M, Noda S, Hanaoka M, Nakayama H, Hojo S, Kakinoki S, et al. AntiToxoplasma antibody prevalence, primary infection rate and risk factors in a study of toxoplasmosis in 4466 pregnant women in Japan. Clin Vaccine Immunol. 2012;19:365-7

27. Yamada H, Nishikawa A, Yamamoto T, Mizue Y, Yamada T, Morizane M, et al. Prospective study of congenital toxoplasmosis screening with use of IgG avidity and multiplex nested PCR methods. J Clin Microbiol. 2011;49:2552-6.

Received: 4 May 2012

Accepted: 13 August 2012 